\title{
ELEMENTOS PARA EL ANÁLISIS DE LAS NECRÓPOLIS DE TUMBAS EXCAVADAS EN LA ROCA: EL CASO DE RIBA CÔA
}

\author{
Iñaki MARTÍN VISO \\ Universidad de Salamanca
}

\begin{abstract}
Resumen
Este trabajo pretende ofrecer algunas pautas para el análisis de uno de los más abundantes restos de la época post-romana en la Península lbérica: las necrópolis de tumbas excavadas en la roca. Para ello, toma en consideración la amplia franja de los territorios occidentales en torno a la Cordillera Central, aunque se centra más intensivamente en la comarca portuguesa de Riba Côa. El estudio se basa en tres aspectos: la cronología de estos enterramientos, la relación con las formas del poblamiento y la plasmación de determinados aspectos sociales. Como resultado de ello, se señala como hipótesis de trabajo su estrecha vinculación con las estructuras comunitarias surgidas tras el colapso del sistema romano.
\end{abstract}

Palabras clave: Necrópolis. Comunidades. Cristianización. Riba Côa. Alta Edad Media

\begin{abstract}
The aim of this paper is the study of some patterns about the cemeteries of graves dug in the rock, which are the most frequent and eloquent remains of the post-Roman age in the Iberian peninsula. The analysis takes into account a vast area, the Western territories around the Central Chain, although it is focused more intensively in the Portuguese district of Riba Côa. The research is based on three issues: the chronology of these burials, their link with the settlement pattern and their social meaning. The result is an explanatory hypothesis that points out their connection with the communitarian structures shaped after the collapse of the Roman system.
\end{abstract}

Key words: Cemeteries. Communities. Christianisation. Riba Côa. Early Middle Ages

\section{Un estudio problemático ${ }^{I}$}

Las tumbas excavadas en la roca constituyen uno de los vestigios arqueológicos más abundantes en la Península Ibérica, con hallazgos que se extienden desde Cataluña hasta Andalucía, aunque quedan al margen determinadas zonas del norte cantábrico.

1 Este trabajo se realiza dentro del proyecto de investigación Frontera y límites interiores en la Península Ibérica (siglos VI-XV), financiado por la DGI del Ministerio de Ciencia y Tecnología. Para su confección se han utilizado datos procedentes de los Inventarios Arqueológicos de las Provincias de Ávila y Salamanca. Agradezco además las informaciones proporcionadas por Jorge Adolfo de Meneses Marques, Jesús Caballero, Jorge Díaz de la Torre, Sónia Filipe, Juan Antonio Quirós Castillo y Juan Carlos Castillo Armenteros, y muy especialmente la ayuda prestada por Carlos Panta y Francisco Saraiva.
Tanto su número como su amplitud geográfica certifican la necesidad de un estudio detallado, no exento de problemas. En tal sentido, es importante observar cómo la casi totalidad de ellas no han conservado restos humanos, carecen de ajuares y se hallan arqueológicamente descontextualizadas. El resultado es que continúan siendo un dato escasamente utilizado en los estudios sobre la Alta Edad Media peninsular. En dicha situación convergen la despreocupación por la arqueología que tradicionalmente ha caracterizado al medievalismo y la consideración ancilar de los periodos post-romano y altomedieval con respecto a las épocas romana y feudal. En el fondo del problema late la menor visibilidad de las elites durante estos siglos, como consecuencia de una reestructuración de las bases de su poder, con una menor presencia del Estado como agente social, una mayor inestabilidad en la consolidación del estatus social y una tendencia a 
reforzar determinadas vías de dominio distintas de la dependencia con respecto al Estado (Wickham, 1989). Este proceso dejó su huella en el espacio, aunque parece tratarse de una aceleración de procesos ya existentes en el Bajo Imperio, que puede definirse en términos generales como una preponderancia de las estructuras asociadas a las comunidades rurales (La Rocca, 1998a). Las tumbas excavadas en la roca deben integrarse en tal proceso.

A lo largo de estas páginas se pretende únicamente ofrecer una serie de reflexiones e hipótesis sobre determinados problemas relacionados con las tumbas excavadas en la roca. El trabajo se estructurará a través de una escala doble. Por un lado, un nivel macro, centrado en una amplia región, los sectores en torno a la Cordillera Central situados entre las sierras de Somosierra y de la Estrella. En esta área, se han podido detectar hasta el momento un total de 534 yacimientos con tumbas excavadas en la roca. En un segundo nivel, se analiza la comarca portuguesa de Riba Côa, integrada dentro de este sector, y sobre la que se ha realizado una labor más intensiva. Esta comarca de la Beira Alta portuguesa ocupa la franja más oriental del actual distrito de Guarda y se trata de un espacio dominado por las altas penillanuras paleozoicas. Aunque el río Côa ha concedido identidad a esta región, en realidad su curso configura un profundo tajo, sin que existan llanuras aluviales que faciliten el cultivo o el emplazamiento de un hábitat humano. En cambio, las ribeiras, cursos de agua de menor cauce que surcan la penillanura, ejercen un papel articulador al proporcionar aluviones que se depositan a lo largo de su paso. Dentro de este conjunto, nuestro análisis se centrará en los territorios pertenecientes a los actuales concelhos de Almeida, Figueira de Castelo Rodrigo y Vilanova de Foz Côa, que componen el área septentrional de la región, extendiéndose por unos $1200 \mathrm{kms}^{2}$, donde se han detectado 44 yacimientos con tumbas excavadas en la roca (Fig.1).

\section{Una cronología de difícil fijación}

Cualquier acercamiento al estudio de las tumbas excavadas en la roca se enfrenta inmediatamente a los condicionantes de una cronología mal definida. El punto de partida es el análisis de A. del Castillo (1970), quien estableció una primera fase, aproximadamente del siglo VII, caracterizada por la presencia de las tumbas de bañera. A ella le seguiría, tras una fase de transición, las denominadas tumbas "olerdolanas" o antropomorfas, que tendrían su periodo de vigencia durante la repoblación por parte de los mozárabes procedentes de al-Andalus en torno a los siglos IX y X. Esta cronología sigue aplicándose en la actualidad (Andrio Gonzalo, 1994; Padilla Lapuente, 2003), a pesar de basarse en una serie de hipótesis e interpretaciones que hoy en día resultan insostenibles. Dicha seriación partía de la consideración de una amplia emigración mozárabe sobre espacios demográficamente vacíos, aceptando las teorías de Sánchez-Albornoz (1966). La investigación ha demostrado en reiteradas ocasiones la inexactitud de tales afirmaciones, tanto en lo que se refiere a la desaparición de pobladores como a la supuesta emigración al norte de los mozárabes (Estepa Díez, 1977; Barrios García, 1982; Aguilar, 1994; Mínguez, 2000; Martín Viso, 2002a). Esta profunda revisión de los postulados historiográficos influye decisivamente en el alcance de la propuesta de A. del Castillo, por otro lado claramente formalista, ya que la secuencia tumbas de bañeratumbas antropomorfas no se basa en criterios estratigráficos, sino en el paso de formas más groseras a otras más elaboradas.

Otros investigadores han planteado propuestas distintas. J. López Quiroga y M. Rodríguez Lovelle (1992) consideran que los inicios de las necrópolis de tumbas excavadas en la roca, incluyendo las antropomorfas, deben situarse a finales del siglo VII, aunque serían entre los siglos VIII al X cuando se produjo su momento de máximo uso. Su presencia se vincularía a ciertos cambios sociales, generándose un poblamiento en áreas hasta entonces marginales (López Quiroga, 2004). En una línea muy similar se mueve el trabajo de M. Barroca sobre el mundo funerario medieval en el norte de Portugal (1987: 130-135). Éste da por buena la diferenciación entre tumbas antropomorfas y no antropomorfas es correcta, a pesar de las numerosas variantes formales en cada grupo, y acepta que las antropomorfas serían posteriores y surgirían en el siglo IX. Pero considera que la evolución al antropomorfismo no tuvo por qué ser sincrónica en toda la Península Ibérica y opta por una mayor flexibilidad regional, al mismo tiempo que descarta el origen mozárabe y repoblador de estas tumbas. Estas propuestas no consiguen, sin embargo, desembarazarse del todo de la carga formalista e historicista. En cambio, algunas excavaciones parecen sugerir una asociación entre estas tumbas y yacimientos de los siglos VI-VII, tanto en Castilla (Reyes Téllez y Menéndez Robles, 1985), como, sobre todo, en la submeseta sur, Andalucía y el Algarve (Gutiérrez Dohijo, 2001; Serrano Peña y Castillo Armenteros, 2000; Gomes, 2002).

En el caso de los territorios en torno al sector occidental de la Cordillera Central, resulta de enorme interés comprobar la existencia de yacimientos en los que conviven diferentes tipos de inhumación, como sucede en varias necrópolis situadas en las serranías 
madrileñas. En el lugar denominado "La Tumba del Moro", a los pies del cerro de La Cabeza, en La Cabrera, se han encontrado diez tumbas, nueve de las cuales son de lajas y otra antropomorfa. Los excavadores han subrayado que las necrópolis de lajas encontradas corresponderían a los siglos VI al VIII, a lo que contribuye el hallazgo de una placa liriforme en una sepultura. Por esa razón, consideran que la tumba antropomorfa no tiene por qué ser posterior, sino que conviviría con las anteriores, situándose cronológicamente en la época visigótica (Yáñez et alii, 1994). Por otro lado, en el yacimiento de "Fuente del Moro" (Colmenar Viejo), además de algunas tumbas de fosa, se han encontrado diez tumbas excavadas en la roca en dos grupos diferenciados, conviviendo tanto formas antropomorfas como no-antropomorfas (de bañera, trapezoidal y rectangular). Los restos asociados a este lugar parecen identificarse con un pequeño hábitat existente en el siglo VII y que perduraría hasta el VIII (Colmenarejo García, 1986).

Las dificultades para establecer una seriación desde criterios formales aparecen también en Riba Côa, donde en varios casos se constata la convivencia de formas antropomórficas y no-antropomórficas. Así sucede en Nave do Moiro (Malpartida, c. Almeida), donde se observa la presencia de 28 tumbas del primer modelo y 8 del segundo (Endovélico). Algo similar ocurre en la iglesia de Freixo de Numão (c. Vilanova de Foz Côa), donde se han detectado ambos tipos -además de otros como tumbas de lajas y de piedras alineadas de granito-, lo que se ha interpretado como la existencia de distintas fases de enterramiento, correspondiendo a los momentos más antiguos las sepulturas de forma ovalada (Coixão, 1999: 132-134). Sin embargo, dicha apreciación no está argumentada por criterios estratigráficos, sino únicamente formales. Aún siendo plenamente cierta la existencia de diversas fases de enterramiento, éstas no tienen por qué responder necesariamente a la evolución de las formas, pudiendo convivir ambas. En cuanto al caso de Nave do Moiro, la articulación en forma de pequeños conjuntos de tumbas, a veces incluso de una sola sepultura, podría responder a fases diferenciadas de uso, pero no hay ningún dato real que certifique que puedan diferenciarse a través de las formas. Quizá el ejemplo más clarificador al respecto provenga de Vale da Igreja (Azinhal, c. Almeida), una pequeña necrópolis de 4 tumbas, todas ellas juntas y emplazadas en un batolito pizarroso de dimensiones reducidas, situada a unos 200 metros al sur del núcleo actual (Perestrelo, 2000: 19). Una de las sepulturas se encuentra muy deteriorada, pero las otras tres presentan una variedad de formas, ya que dos son antropomórficas y otra no (Fig.2). Todo indica que la variación en las formas no puede resolverse a través de una evolución cronológica, sino que responde a cuestiones estilísticas que escapan al encuadramiento temporal del fenómeno. Esto es aún más evidente si se observa la clara preponderancia de las formas antropomórficas frente a las no-antropomórficas en los yacimientos ribacudanos, aspecto que llevaría a pensar que antes del siglo VIII la gente se enterraba menos o no se enterraba, porque tampoco se evidencia la presencia de tumbas de lajas. Este hecho se constata igualmente en otras zonas, donde destaca la neta preponderancia numérica de las tumbas antropomórficas con respecto a las no-antropomórficas (Marques, 2000; Tente y Lourenço, 1998), aunque hay excepciones (Vieira, 2000).

La negación de la secuencia cronológica definida por el paso de tumbas no-antropomorfas a las antropomorfas se acompaña la constatación de que el uso de estas necrópolis se inició antes del siglo VIII y que dicha centuria no marca ninguna cesura, sino una continuidad. En la región de Viseu, sobre un total de 168 yacimientos, al menos un $45 \%$ de ellos se hallaban cercanos a lugares donde se han encontrado materiales romanos comunes, que podrían incluso datarse en períodos posteriores (Marques, 2000: 218). Esta situación se repite en la Sierra de Gata cacereña, donde se ha observado la asociación de estas necrópolis con la aparición de tégulas, datadas de una manera bastante dudosa en época tardorromana, pudiendo continuar su uso en fechas posteriores (García de Figuerola Paniagua, 1999: 71). De todos modos, la datación de algunos materiales como tardorromanos o visigodos es problemática, ya que se trata de cerámicas de construcción que pueden situarse en épocas posteriores o materiales hallados en superficie e incluso en posiciones secundarias. Debe añadirse que no es seguro que exista una secuencia sincrónica entre el uso de las tumbas y el de tales materiales, que se hallan siempre en zonas relativamente alejadas (Tente y Lourenço, 1998). No obstante, otros datos abogan por la hipótesis de un origen tardoantiguo de estas necrópolis. Uno de ellos es la presencia de algunos materiales decorativos procedentes de ajuares funerarios de tradición tardoantigua, como los hallados en las necrópolis de El Berrueco (El Tejado, Salamanca) y Nuestra Señora de los Remedios (Colmenar Viejo, Madrid) ${ }^{2}$. Pero quizá el más llamativo es la asociación de estas necrópolis con determinados lugares que pueden ser identificados como vici o villae. Es el caso de la necrópolis de Plames, en Vilares (Trancoso) (Perestrelo, 2000: 83; Ferreira, 2000: 369), Vale de El Rei (Marialva, c. de Meda) (Perestrelo, 2000: $47-$

2 Datos del Inventario Arqueológico de la Provincia de Salamanca y de Colmenarejo García, 1987: 13-17. 
48) o Campas (Mangualde) (Marques, 2000: 84; Tavares, 1999: 43-44).

En el caso de Riba Côa, al menos 15 de los yacimientos con tumbas excavadas en la roca se relacionan con posibles restos de época romana. En algunas ocasiones se trata de sitios de cierta importancia a tenor de los restos hallados, como Verdugal (Malhada Sorda, c. Almeida), donde se han identificado los restos de un posible vicus o villa a través del hallazgo en superficie de fragmentos de cerámica de construcción y común doméstica, así como algunos molinos circulares, mosaicos, capiteles y una moneda de Trajano y otras del siglo IV. En el pago de Moradios, en una zona algo separada del principal núcleo de hallazgos, se han encontrado once sepulturas excavadas en la roca (Silva, 2000a: II, 34; Perestrelo, 2000: 79-80 y 169). Este lugar pudo estar ocupado más allá del siglo IV, modificando su ordenación, quizá con la presencia de un hábitat en materiales ligeros, y dicha secuencia coincidiría con el uso de las tumbas, emplazadas fuera de la zona de hallazgos, pero en sus inmediaciones. También en Telhões (Leomil, c. Almeida) se puede comprobar la existencia de un yacimiento de época romana de cierto relieve, en cuyas inmediaciones se conserva una tumba excavada en la roca (Perestrelo, 2000: 22) (Fig. 3). Aunque estos datos parecen confirmar la idea de que las primeras fases de la utilización de las tumbas excavadas en la roca, tanto en Riba Côa como en general en el centro peninsular, deben situarse en los siglos tardoantiguos, la asociación de las necrópolis con tales centros de hábitat romanos es, de todos modos, compleja. Las razones estriban en que no se ha constatado de manera fehaciente que exista una conexión sincrónica entre los yacimientos, que pueden corresponder a momentos distintos de ocupación, y en el hecho de que no es segura la adscripción vilicaria de los núcleos señalados. La ausencia de ajuares y la inexistencia de dataciones absolutas lastran cualquier precisión cronológica. Como hipótesis, puede plantearse que estos lugares sufrieron una remodelación en época tardoantigua marcada por los cambios en la pars urbana, transformada en una zona de hábitat con construcciones de materiales perecederos $\mathrm{o}$ en espacios funerarios, como se ha observado en otros ámbitos peninsulares (Chavarría Arnau, 2001), produciéndose entonces la eclosión del cementerio. Aunque siempre como hipótesis, la reiteración de los datos en este sentido permite aventurar un origen tardoantiguo de las necrópolis de tumbas excavadas en la roca.

De todos modos, los siglos VIII al X marcaron posiblemente el apogeo de esta forma de enterramiento, muy ligada a unas coordenadas sociales específicas. Por otro lado, el término ante quem de estas necrópolis parece más o menos claro, a tenor de su localización, habitualmente fuera de las aldeas, en pagos situados a veces a varios kilómetros, como se comprueba en el valle del alto Manzanares (Madrid) (Colmenarejo García, 1986; Morere Molinero, 1986). Cuando se advierte su presencia en el interior de las localidades, suelen encontrarse en las cercanías de las iglesias parroquiales, cuyos muros han amortizado el antiguo cementerio de tumbas excavadas en la roca. Es el caso de Santa Maria, en Moreira de Rei (Trancoso) (Ferreira, 2000: 367), en la iglesia de Castelo (Moimenta da Beira) o Vouzela (Marques, 2000: 94-96 y 181-182). Por tanto, se puede afirmar que el momento de finalización del uso de estas necrópolis debe situarse en la consolidación del poblamiento aldeano y de la parroquia como centro de culto y eje de la articulación rural.

El emplazamiento al margen de las aldeas representa también una pauta común a los yacimientos ribacudanos, ya que únicamente en 6 casos se observa una relación entre estas tumbas y asentamientos actuales. Incluso cuando se constata esa localización, se trata de sepulturas que han quedado descontextualizadas y que responden a fases previas a la configuración de la aldea. Así ocurre en Leomil (c. Almeida), donde subsiste una sepultura antropomórfica en las cercanías de la iglesia parroquial, aunque sin conexión con ésta, y otra que se utiliza como pila en la fuente del pueblo. Parece desprenderse de ello que las necrópolis de tumbas excavadas en la roca serían anteriores a la configuración de las aldeas y de la red parroquial. En el caso de Riba Côa, no se pueden establecer con claridad las fechas de este proceso, que, de todos modos, ha de entenderse como gradual. Los textos escritos, que únicamente comienzan a ser frecuentes a partir de la segunda mitad del siglo XII, parecen referirse a localidades que ya se encuentran plenamente configuradas. Para entonces ya se habría producido una concentración del hábitat en determinados núcleos, lo que podría haber desembocado en una centralización de los lugares de culto. De todos modos, la creación y consolidación de la red parroquial aceleró ese proceso y favoreció el cambio en las prácticas inhumatorias, ahora concentradas en las parroquias. Los documentos escritos parecen evidenciar que dicha red ya estaba plenamente desarrollada a principios del siglo XIII, como se pone de manifiesto en el acuerdo entre Santa María de Aguiar y el obispo de Ciudad Rodrigo sobre los diezmos de dicha diócesis en los lugares que pertenecen al monasterio (ANTT, Santa María de Aguiar, maço 4, doc. 271). Por otro lado, el listado de 
los beneficios parroquiales en el reino portugués en 1320 pone de manifiesto la definitiva implantación de ese modelo (ANTT, Santa Cruz de Coimbra, livro 97). Estos datos coinciden con las pocas noticias proporcionadas por el registro arqueológico. Así, las prospecciones efectuadas en las cercanías de los sitios con tumbas excavadas en la roca no ofrecen restos de época plenomedieval, aunque se han detectado algunas cerámicas comunes, datadas como medievales, en las inmediaciones de Cova da Moira (Algodres, c. Figueira de Castelo Rodrigo), Milreiro (Almofala, c. Figueira de Castelo Rodrigo), São Marcos de Palumbeira-Fontanares (Cinco Vilas, c. Figueira de Castelo Rodrigo) y Tapada da Eira (Freixo de Numão, c. Vilanova de Foz Côa) (Coixão, 2000: 345; Cosme, 2002: 20-22, 40, 46, 50; Perestrelo, 2000: 25-26). Igualmente los centros de culto desligados de las redes parroquial y monástica, como Prazo o Quinta da Ervamoira (Coixão, 1999; Guimarães, 2000), parecen abandonarse entre los siglos XII y XIII, aunque en las últimas fases de ocupación se aprecia claramente un cambio en el tipo de tumbas. En definitiva, podría aceptarse que el final de la utilización de las tumbas excavadas en la roca debe situarse hacia el siglo XI, al menos en Riba Côa, como consecuencia de las transformaciones en la ordenación social del territorio.

Estas fechas no tienen por qué ser similares en todos los casos, ya que el proceso de formación y consolidación de aldeas y parroquias no fue sincrónico en todas las regiones. No obstante, la tardía cronología del caso ribacudano es semejante a la que se detecta en otras áreas de la región, como las serranías madrileñas (Martín Viso, 2002b), la cercana Sierra de Gata (Sánchez Cabañas, 2001: 187; Martín Martín, 1989: doc. 11) o las áreas de la Beira portuguesa (Da Costa y Marques, 1990: doc. 71). La documentación estaría reflejando un proceso probablemente de origen previo, que podría retrotraerse a los siglos X y XI, cuando figuran ya algunas aldeas y se restauran ciertos obispados, aunque la definitiva implementación del sistema parroquial fue relativamente tardía en todo este sector peninsular.

Por tanto, debieron existir numerosas variaciones zonales que impiden establecer una cronología fija y exacta que sirva para todas las zonas. A pesar de ello, y tras desestimar la secuenciación a través de la supuesta sucesión de formas, puede hablarse genéricamente de una fecha post quem en torno a los siglos VI-VII, dependiendo de las zonas. Este tipo de necrópolis se extendió en el territorio con la cristianización rural, perpetuándose en el tiempo, sin que se pueda detectar de manera fiable un cambio en el siglo VIII. Su final coincide con el complejo y plural proceso de formación y consolidación del entramado aldeano y parroquial, que habría terminado, dependiendo de las zonas, entre los siglos XI y XII.

\section{Las necrópolis y la articulación del territorio y del poblamiento}

La investigación sobre las necrópolis de tumbas excavadas en la roca se ha preocupado muy poco por profundizar en las relaciones que éstas tenían con la organización del territorio y del poblamiento. Las pocas reflexiones que se han efectuado al respecto han pivotado sobre dos explicaciones. La primera, y más tradicional, es la que las conecta con poblados de repoblación, en especial de mozárabes (Castillo, 1972; Andrio Gonzalo, 1994). La segunda es la que vincula a estos yacimientos con un hábitat disperso (Barroca, 1987; López Quiroga y Rodríguez Lovelle, 1999; Marques, 2000: 216). Éste habría surgido tras la época romana, como probaría su emplazamiento en zonas consideradas marginales en los siglos anteriores. Además no puede identificarse con las aldeas medievales, debido a que generalmente se encuentran fuera de esos núcleos. Si a ello se añade que, al menos en gran parte de las comarcas del Noroeste y del centro peninsular, el número de las tumbas suele ser muy escaso y que poseen un nítido patrón de dispersión, parece lógico pensar que sean huellas de un hábitat disperso producto de la iniciativa campesina. Tal hipótesis plantea algunos problemas, ya que no se han podido descubrir los restos de esos poblados, aunque es cierto que tampoco se han buscado y que debieron construirse con materiales poco reconocibles a partir de una prospección de superficie, como la madera (Azkarate Garai-Olaun y Quirós Castillo, 2001). Por otra parte, aún siendo plenamente posibles la existencia y perduración de este hábitat disperso, algunos estudios realizados en otras áreas del Mediterráneo occidental ponen de manifiesto la presencia relativamente temprana de asentamientos concentrados (Francovich y Hodges, 2000), circunstancia que también se observa en ambas mesetas (Nuño González, 1997-98; Vigil-Escalera Guirado, 2000). Por último, esta hipótesis no explica las razones que empujaron a los campesinos a ocupar tierras inhóspitas, cambiando completamente sus modos de vida, únicamente a causa de la desestructuración del modelo vilicario, que en absoluto dominó el paisaje rural romano en el centro y norte de la Península Ibérica.

Todas estas dudas no invalidan, sin embargo, la hipótesis de que hubiera un patrón disperso, pero hacen necesario profundizar en su estudio. Las informaciones procedentes del sector occidental de la Cordillera Central refrendan la imagen inicial sobre las necrópolis de tumbas excavadas en la roca. En 
primer lugar, puede observarse cómo el número de sepulturas por cada yacimiento se sitúa mayoritariamente por debajo del umbral de las 5 tumbas. Teniendo en cuenta que existe una serie de necrópolis de las que carecemos de referencias acerca del número de tumbas (65), habría 393 sitios, es decir un $83,8 \%$ sobre el total corregido (469 necrópolis). Si elevamos la cifra hasta 10 inhumaciones, el porcentaje alcanza el 92,3\%, pues únicamente 37 de los yacimientos superan ese número de sepulturas. Estos valores se ajustan perfectamente a los datos que proporcionan algunas investigaciones sobre espacios concretos, que subrayan también ese bajo número de inhumaciones por lugar (González Cordero, 1998; García de Figuerola Paniagua, 1999; Marques, 2000: 185-186; Tente y Lourenço, 1998). Por consiguiente, el patrón habitual es el de tumbas aisladas, normalmente una o dos, emplazadas en pleno campo. Precisamente sólo 22 de los sitios reconocidos en la base de datos se encuentran situados dentro de poblaciones actuales, lo que representa apenas un $4,1 \%$ del total. Esta apreciación quizá se relacione con un modelo de poblamiento distinto de las aldeas consolidadas en la Plena Edad Media, si bien ha de tenerse en cuenta el arrasamiento de las estructuras funerarias en los lugares que han estado ocupados en los últimos mil años. Otro dato muy significativo es que la relación entre estas tumbas y los centros de culto no es muy común. La base de datos arroja únicamente 73 casos en los que se detecta esa conexión (13,7\% sobre el total), incluyendo no sólo las inhumaciones halladas en iglesias parroquiales o en capillas, sino también las referencias a hagiotopónimos. Este resultado contrasta con lo que se propone como tendencia en otras áreas peninsulares, como Castilla (Andrio Gonzalo et alii, 1993; Padilla Lapuente, 2003) -aunque esa imagen puede estar distorsionada por la prioridad otorgada a la intervención en los centros de culto, mientras que otros estudios ponen de manifiesto una situación similar a la que aquí se expone (Martín Viso, 2000; Escalona Monge, 2002: 71)-, y la región entre el Duero y el Miño (López Quiroga, 2004: 157). Esta diferenciación podría también ser consecuencia de una dinámica social distinta que afectó a la organización del territorio.

La imagen resultante es la de unas necrópolis con un número bajo de inhumaciones -pudiéndose advertir, de todos modos, la existencia de reocupaciones-, situadas mayoritariamente fuera de las aldeas plenomedievales y sin una relación clara con centros de culto, ni actuales ni desaparecidos. Sin duda tales rasgos parecen inclinar la balanza hacia un hábitat disperso, posteriormente desaparecido. A pesar de ello, es conveniente relativizar la escasez de tumbas.
Allí donde se han conservado un mayor número de tumbas, se observa la existencia de un patrón disperso del cementerio, como sucede por ejemplo en São Gens (Forno Telheiro, c. Celorico da Beira), Tapada do Anjo (Vila Ruiva, c. Fornos de Algodres) o El Alcorejo (Becerril de la Sierra, Madrid) (Rodrigues, 1992: 31-34; Marques, 2000: 64-68; Valera, 1993: 38-39; Morere Molinero, 1986). En vez de concentrarse las tumbas en torno a un determinado punto, las inhumaciones aparecen en grupos reducidos que se extienden por un terreno amplio. Esta distribución podría ser más común de lo que se ha considerado, por lo que las sepulturas aisladas en realidad serían un vestigio de necrópolis más extensas, de patrón disperso, muchas de ellas arrasadas por los campos de cultivo o por el uso de las piedras para construir muros. Esta situación puede advertirse cuando se encuentran varios de estos focos relativamente cercanos, aunque separados, lo que ha llevado a identificarlos como yacimientos diferenciados, cuando podría tratarse de una misma área extensa de inhumación. Así ocurre, por ejemplo en Casas de Prado Álvaro I y II (Casillas de Flores, Salamanca) o en Carvalhais A y B (Vila Nova de Paiva) (Marques, 2000: 144-146).

Centrándonos en el caso de Riba Côa, y una vez eliminados 5 yacimientos de los que no disponemos de datos fiables sobre el número de tumbas, existirían un total de 27 sitios que se sitúan por debajo del umbral de las 5 sepulturas $(69,2 \%)$, y si ampliamos hasta 10 inhumaciones, el número de yacimientos por debajo de esa cifra se eleva a $32(82,1 \%)$. Estos valores implican que, dentro del conjunto regional, el número de inhumaciones por sitio es algo más elevado, pero el comportamiento se enmarca en las pautas generales, resultando bastante habituales los hallazgos de una o dos tumbas descontextualizadas. Sin embargo, algunos casos ponen de relieve la presencia de una articulación basada en una distribución laxa, como ocurre en Nave do Moiro (Malpartida, c. Almeida), Tapada da Raposeira (Vermiosa, c. Figueira de Castelo Rodrigo) o Mimosa (Mata de Lobos, c. Figueira de Castelo Rodrigo). La primera de ellas, compuesta por 37 tumbas, se extiende por una superficie amplia en la que se encuentran algunos pequeños aglomerados, situación que se repite en los otros dos casos. Es probable que buena parte de las sepulturas se hayan destruido y que sólo se conserven algunas de ellas en determinadas zonas, lo que daría la imagen de esa fragmentación. Resulta igualmente interesante comprobar cómo algunos núcleos pudieron disponer de varios focos de enterramiento. Es el caso de Colmeãl de Almofala, un despoblado del siglo XVI, pero que figura como aldea a principios del XIII (Da 
Costa y Marques, 1990: doc. 100). Se trataría de un caso similar al de La Genestosa (Casillas de Flores, Salamanca), donde un mismo poblado tiene en torno a sí al menos tres focos de inhumaciones. Por otra parte, la cercanía de algunas tumbas con otras, a pesar de su diferenciación en sitios distintos, apunta la posibilidad de que se trate de vestigios aislados de una misma zona de inhumación. Así sucede con Fonte da Eira y Laja Namorada, dos lugares situados en Paraisal do Côa, compuestos el primero por 4 tumbas, una de las cuales es un sepulcro integrado en un muro de propiedad, y el segundo por dos sepulturas antropomórficas (Endovélico); ambos sitios se hallan a muy escasa distancia entre sí, por lo que podían responder a esa situación. Incluso cuando se trata de unas pocas tumbas, éstas se encuentran dispersas por el espacio, como ocurre con las siete tumbas que componen el yacimiento de Ribeiro de Forno-Campanas (Castelo Bom, c. Almeida) (Endovélico) o las de Colmeãl de Almofala, donde se pueden observar al menos tres, una de las cuales, quizá doble, forma parte de un muro de propiedad ${ }^{3}$. Este fenómeno es bastante frecuente y se aprecia en otros yacimientos de los territorios en torno a la Cordillera Central ${ }^{4}$.

Otra circunstancia que ha de tenerse en cuenta es la cercanía de estas necrópolis a determinadas vías locales, conservadas en forma de carreteras o de caminos que unen a determinadas aldeas. Así se observa en la vertiente meridional de la Sierra de Gata (García de Figuerola Paniagua, 1999) o en el concelho de Fornos de Algodres (Valera, 1993). En otras ocasiones, será necesario leer detenidamente la red de caminos, a través de mapas y de fotografía aérea, para comprobar cómo la red viaria local permite el acceso a estos yacimientos, si bien en numerosas ocasiones las profundas alteraciones del paisaje rural han modificado tal estructura. E igualmente es interesante comprobar el emplazamiento de las tumbas en relación con los cursos de agua, en especial con determinados arroyos. Por último, varios estudios han puesto de relieve la proximidad de hallazgos en superficie de materiales de época tardorromana o altomedieval -

3 Hemos podido ver esta necrópolis con la ayuda de Francisco Saraiva y utilizamos los datos que hemos recogido. Cosme, 2002: 38-39 señala la presencia de otra tumba más, que no pudimos observar.

4 Así sucede en Ourigos (Decermilo, c. Satão), A do Conde (Lamosa, c. Sernancelhe), El Maguillo (Sorihuela, Salamanca), El Rotoro (Navasfrías, Salamanca) o Fuente de la Zorra (Cabezas del Villar, Ávila). Marques, 2000: 122-123; 131; Vieira, 2000: $\mathrm{n}^{\circ}$ 62; Fabián et alii, 1986: 200; Inventario Arqueológico Provincial de Salamanca; Inventario Arqueológico Provincial de Ávila. especialmente cerámicas de construcción y comunescon respecto a estas tumbas, situadas a unos pocos centenares de metros a lo sumo. Así sucede en la región de Viseu (Marques, 2000) y en ambas vertientes de la Sierra de Gata (García de Figuerola Paniagua, 1999; Inventario Arqueológico Provincial de Salamanca). Es verdad que únicamente 104 de los 534 yacimientos inventariados $(19,5 \%)$ puede identificarse con esta tipología, pero debe tenerse en cuenta que en muchas ocasiones no se ha prospectado detenidamente las zonas cercanas.

En el caso de Riba Côa se observan tres factores recurrentes en la localización de estas necrópolis: el emplazamiento en áreas de difícil uso para el cultivo, la localización relativamente cercana, aunque siempre a una cierta distancia, en relación con las ribeiras y la conexión con la red vial local. Así ocurre en la zona de la ribeira de Aguiar, cerca de Castelo Rodrigo, donde lugares como Galeotas y Vale de Moinhos responden a estas características (Endovélico; Cosme, 2002: 69-70). Se puede observar cómo las tumbas se encuentran en las cercanías de las ribeiras, aunque fuera de las llanuras aluviales, y conectadas por una red de caminos rurales que perdura en la actualidad. En otros casos, la ribeira está algo más distante, aunque no muy lejos, y la necrópolis se sitúa en un sector alejado de la llanura aluvial y poco propicio para el cultivo, pero bien conectado por la red local, como ocurre en Nave do Moiro. Todo ello parece indicar que existen áreas específicas destinadas al enterramiento, emplazadas en lugares cercanos a las áreas de residencia y de cultivo, pero separadas de éstas. Más difícil es establecer cuáles eran los lugares de hábitat asociados a estas necrópolis, quizá emplazados en la vecindad de los lugares de enterramiento, a tenor de la presencia de pequeños núcleos con posible ocupación altomedieval, como Fontanares (Cinco Vilas, c. Figueira de Castelo Rodrigo), Luzelos (Bizarril, c. Figueira de Castelo Rodrigo) o Vigia (Castelo Bom, c. Almeida) (Perestrelo, 2000: 27, 73; Cosme, 2002: 51) (Fig. 4).

El análisis de una pequeña zona, como es el caso de las necrópolis situadas en torno a la ribeira $d a$ Devesa, puede ser ilustrativo. En la margen derecha del cauce -actualmente represado-, y dentro de los términos de la localidad de Vermiosa, a unos 3 kilómetros al suroeste, se encuentra la necrópolis de Tapada da Raposeira, donde se han conservado 22 tumbas excavadas en la roca, que se extienden por una plataforma granítica a partir de sepulturas aisladas o en grupos de dos. En las cercanías de este lugar se han hallado igualmente fragmentos de cerámica común y de construcción, así como se aprecia la existencia de ciertas estructuras soterradas que parecen corresponder a un hábitat altomedieval 
(Cosme, 2002: 78; Endovélico). Esta necrópolis no parece relacionarse con ningún asentamiento conocido por los textos escritos, mientras que el lugar de Vermiosa aparece ya a mediados del siglo XII configurado como aldea (Palacios Martín, 2000: doc. 12; González, 1944: doc. 47). Por tanto, cabe conjeturar que el hábitat debió desfuncionalizarse antes del siglo XII y se formó después del periodo romano, ante la ausencia de materiales de esa época. La necrópolis se asienta sobre unos suelos graníticos difícilmente aprovechables, formando un espacio cercano, pero separado del hábitat, y a una cierta distancia de la ribeira, aunque en sus cercanías. La red vial local permite una fácil conexión con este lugar, a través de un camino que, partiendo de la carretera que une Vermiosa con Malpartida, sale hacia el oeste, en dirección a la ribeira. En la margen izquierda encuentra la Quinta de Vilar Tomé, actualmente una pequeña granja en el término de Reigada, pero que en época medieval fue una aldea (González, 1980-86: doc. 805). Aquí existen tres sepulturas excavadas en la roca situadas en un bolo granítico cercano a una construcción que amortiza una antigua capilla. Las prospecciones realizadas han encontrado tégulas y se ha afirmado una ocupación en época romana y visigoda (Cosme, 2002: 75). Aunque se trate de una adscripción cronológica muy dudosa, parece que pudo existir un hábitat en las cercanías de la necrópolis. El emplazamiento repite el modelo ya observado en Tapada da Raposeira, con una relativa cercanía a la ribeira de Devesa, aunque apartada de ella, utilizando un espacio de emergencias graníticas y con una adecuada conexión a través de un camino que, saliendo de la carretera que va a Almeida, se dirige hacia el Este a dicho lugar (Fig. 5)

Estos elementos permiten inferir que la articulación del territorio rural que reflejan las necrópolis implica una articulación espacial a través de áreas funcionalmente diferenciadas. Dicho modelo, basado en la separación de áreas residenciales, espacios de cultivo y zonas de uso funerario, donde éstas se hallaban cerca de determinadas vías de uso local, también puede comprobarse en algunos centros intermedios fortificados, como Numão. Volviendo al ámbito estrictamente rural, hay que valorar la conexión entre los yacimientos con tumbas excavadas en la roca y los sitios con cerámicas comunes y de construcción, que quizá sean el vestigio de los poblados relacionados con las necrópolis, pero separados de éstas. Existía así un espacio funerario específico, generalmente no centralizado, donde las sepulturas se extendían por el terreno sin un orden prefijado, y en el que podía haber en algunas ocasiones -aunque desde luego no en la mayoría- un nexo con ciertos lugares de culto que no funcionaban como parroquias, sino simplemente como ejes de la religiosidad popular. El espacio funerario debía estar bien conectado con el hábitat a fin de facilitar el tránsito hacia él. Pero al mismo tiempo, se encontraba forzosamente al margen de las zonas de aprovechamiento agrario y ganadero. De ahí que su emplazamiento eluda las áreas más próximas a los cursos de agua, sobre todo cuando éstos proporcionan zonas aluviales, e igualmente sucede con los espacios que pudieran utilizarse como pasto.

Por otro lado, la débil relación entre centros de culto y las necrópolis parece relacionarse con una ausencia de centralización eclesiástica de los usos funerarios. Esta situación no impidió la concentración de tumbas en determinados loca sacra que pudieron adquirir una gran influencia entre la población, como sucede con el monasterio de São Julião de Mangualde, donde se han encontrado 44 tumbas debajo de los cimientos de la iglesia dionisina (Pinto, 1983). En otras ocasiones, esa concentración tuvo que ver con la presencia de iglesias de especial relevancia en ámbitos comarcales, consagradas posteriormente como parroquias, cuyas estructuras amortizaron las anteriores necrópolis, como ocurriría en Vouzela (Marques, 2000: 179-180). Sin embargo, lo más habitual debió ser que, en aquellos casos donde la necrópolis se conectaba con centros de culto, éstos quedaran fosilizados como ermitas o capillas.

Volviendo al ejemplo de Riba Côa, únicamente se detectan 10 yacimientos que parecen asociarse con algún centro de culto $(22,7 \%)$, aunque algunas necrópolis parecen ser anteriores a los loca sacra con los que se asocian, como sucede en Santa María de Numão y puede sospecharse que en otros más. De todos modos, se observa claramente cómo existe un patrón de fuerte concentración que caracteriza a las necrópolis situadas en torno a determinados centros de culto de época altomedieval. Uno de ellos es la iglesia prerrománica de São Pedro de Numão, donde pueden observarse unas 19 tumbas en un espacio reducido, habiéndose perdido algunas más. Pero también puede destacarse el lugar de Prazo (Freixo de Numão, c. Vilanova de Foz Côa), donde se construyó un primer centro de culto, datado en época tardorromana o tardoantigua por la presencia de ciertos fragmentos cerámicos. En torno a este lugar se creó una pequeña necrópolis que posteriormente se incrementó en época altomedieval, al tiempo que se llevó a cabo la ampliación del recinto cultual, que probablemente perduró hasta el siglo XII o XIII (Coixão, 1999). Se trataría de un centro de culto posiblemente dotado de cierto prestigio local, pero que no constituyó finalmente un eje parroquial ni un 
monasterio ligado a las redes principales, por lo que decayó su importancia. En cambio, sí adquirió ese rango la iglesia de Freixo de Numão, en cuyo atrio se encontró una primitiva necrópolis, con sepulturas excavadas en la roca (Coixão, 1999: 132-134). El origen de estos lugares no tiene por qué haber sido una parroquia temprana, sino lugares de culto utilizados por los pobladores. En cualquier caso, no se trata de una relación habitual y las áreas destinadas a la inhumación no suelen encontrarse unidas a centros de culto.

Esta configuración del territorio local se ajusta claramente a la ausencia de una estructura eclesiástica centralizada y a un modelo presidido por la vertebración espacial a cargo de las comunidades. Pero los datos de los que disponemos no permiten hablar fehacientemente de un hábitat disperso. Sin duda se trata de una hipótesis coherente, ya que la abundancia de estas necrópolis podría indicar la existencia de una red compuesta por un número mayor de entidades que en época plenomedieval. Sin embargo, los resultados distan de ser definitivos, sobre todo porque existen ejemplos de asentamientos concentrados, en especial los núcleos intermedios en altura, y porque no está plenamente demostrada la conexión entre tumbas y afloramientos de cerámica. En realidad, las tumbas excavadas en la roca no reflejan necesariamente un poblamiento disperso, aunque tampoco lo desmienten; han de ser otros datos los que corroboren o modifiquen esa hipótesis. Nuestra opinión es que el hábitat tardoantiguo y altomedieval en esta zona de la Península Ibérica estaba vertebrado en torno a núcleos relativamente pequeños, compuestos de distintos focos de hábitat, aunque interconectados entre sí, con una disposición laxa y flexible. Otra cosa muy distinta es su vinculación con un proceso de abandono de las áreas centrales en época romana en beneficio de las periféricas, a causa de la crisis vilicaria. Aunque no podemos aquí profundizar sobre ese asunto, no parece que tal situación se haya producido, como puede comprobarse en la región de Madrid, donde junto a la existencia de un hábitat identificado por las necrópolis de tumbas excavadas en la roca en las áreas serranas -periféricas en términos del sistema vilicario romano-, se detecta claramente la vigencia de varios poblados en las zonas sedimentarias, surgidos tanto de las transformaciones de ciertas villae como de iniciativas ajenas a ese patrón (VigilEscalera Guirado, 2000).

\section{Las necrópolis como reflejo de una sociedad}

El estudio de los enterramientos en la roca debe integrarse en el análisis de la sociedad que los ha generado, aspecto que apenas ha merecido la atención de los investigadores. Los trabajos realizados en otras zonas europeas han resaltado el carácter de escenario del poder que representan las necrópolis. Un elemento destacado es la deposición de ajuares, en especial de objetos que simbolizaban la riqueza o el poder. Tales materiales servían para subrayar el prestigio y estatus social de determinadas familias en un momento en el que los lazos tradicionales de legitimación del predominio local se habían convertido en menos efectivos y nuevos grupos de poder competían por el dominio. Dado que el rito de inhumación exigía la presencia de una audiencia, la deposición representaba públicamente el dominio social, en un contexto de inestabilidad social. La conclusión es que el enterramiento con ajuar reflejaba una sociedad donde el poder local estaba abierto y, en consecuencia, era inestable (Halsall, 1997: 66-67; La Rocca, 1998b). Pero esta situación se fue modificando a lo largo del tiempo y se observa cómo en los siglos VII y VIII se produjo una disminución en la riqueza de los ajuares, acelerándose la tendencia hacia la consolidación del enterramiento sin ajuar. En este cambio convergieron diversos factores, como el aumento de la estabilidad del poder local con la subsiguiente consolidación de los cauces de dominio y la influencia de la Iglesia, cuya proyección social permitió que buena parte de la inversión aristocrática destinada a fortalecer su estatus se dirigiera precisamente hacia ciertos centros de culto locales o hacia nuevas prácticas distributivas (La Rocca, 1998a y 1998b).

El caso que nos ocupa presenta rasgos bastante distintos, sobre todo por la ausencia generalizada de ajuares. Son muy escasos los objetos que han podido recuperarse de las tumbas y generalmente se trata de hebillas y fíbulas, pero nunca de armas o símbolos de poder. La práctica inexistencia de estos materiales se relacionaría con una práctica funeraria en la que no era necesaria la deposición de objetos. Tal circunstancia parece enlazar con la ausencia de una fuerte competitividad por el control del dominio local, pero también debe vincularse con la introducción y expansión del cristianismo en estos ámbitos. Por consiguiente, las necrópolis de tumbas excavadas en la roca no parecen haber sido el escenario donde se visualizaba la competencia por el dominio en una escala local o comarcal. Si acudimos al caso de Riba Côa, se constata un hecho revelador: no hay ningún resto de ajuares en las diferentes necrópolis. Desde luego esta afirmación debe relativizarse en la medida en que una abrumadora parte de las tumbas han aparecido vacías, 
posiblemente como consecuencia de algún tipo de violación. A ello se suma que allí donde se han conservado restos humanos, resulta evidente la reutilización de las tumbas, como ocurre en Prazo (Coixão, 1999). Sin embargo, este yacimiento es también una prueba palpable de que, no obstante las cautelas que se han señalado, la ausencia de ajuares debía ser la norma, incluso para periodos tardoantiguos. De hecho, ninguna de las siete sepulturas de la primera fase (siglos V-IX) ha proporcionado materiales, a pesar de no haber sido violadas. Es interesante advertir además que estamos ante uno de los ejemplos de transformación de una antigua estructura romana en un centro de culto, un cambio que reflejaría además las alteraciones en el sistema social y en la articulación del estatus.

No obstante, se ha postulado que las sepulturas situadas en pequeños roquedales que se alzan sobre el terreno estarían relacionadas con la plasmación de la jerarquización interna. En la zona meridional de Galicia y en el norte de Portugal este tipo de emplazamientos es muy frecuente (Barroca, 1987; López Quiroga, 2004), situación que se repite en el sector que nos ocupa, donde al menos se han podido inventariar 54 casos $(10,1 \%$ del total). Dicha circunstancia se ha explicado como una muestra de la voluntad del enterrado y de su familia de disponer de una sepultura bien destacada en el paisaje. Esta interpretación quizá resulte operativa cuando se trata de pequeños conjuntos de una o dos tumbas, muy frecuentes en las comarcas en torno a la Cordillera Central. En el caso de Riba Côa, sólo 7 de los yacimientos responden a este modelo, lo que representa un 15,9\%. Un ejemplo es Cabeço de Milreiro (Mata de Lobos, c. Figueira de Castelo Rodrigo), donde se ha podido detectar la presencia de al menos dos tumbas que se encuentran en la ladera de un pequeño cabezo rocoso. Su emplazamiento, sin embargo, no parece representar una preeminencia espacial, ya que no están en lo alto del roquedo. Este hecho hace dudar de la hipótesis sobre la preponderancia social, ya que la localización en tales berrocales podría estar vinculada a la dedicación funeraria de zonas baldías para el cultivo o el pasto, como son dichos roquedales. En el caso de conjuntos amplios de tumbas, auténticas necrópolis, la evidencia parece inclinarse hacia la opción de un emplazamiento en zonas baldías. En Riba Côa no hay datos acerca de este tipo de amplias necrópolis situadas sobre cerretes, aunque una causa determinante es el predominio paisajístico de la penillanura. En cambio, otros cementerios del sector occidental de la Cordillera Central, como Carvalhais (Vila Nova de Paiva) o Forcadas (Matança, c. de Fornos de Algodres) (Marques, 2000: 56-60, 145-
146; Valera, 1993: 37), responden a ese patrón, por lo que su localización podría estar reflejando precisamente el uso de áreas de menor potencialidad económica para la inhumación.

Las tumbas en torno a centros de culto parecen ofrecer mayores pistas sobre la plasmación del estatus. Ya se ha podido constatar cómo se trata de focos en los que se detecta una tendencia acusada a la concentración de las tumbas. El prestigio de estos centros debió de ser la causa de que hubiera una preocupación por ser enterrado en sus inmediaciones, ad sanctos. Algunos casos parecen representar claramente ese proceso, como ocurre en Lourosa da Serra, sede de un centro eclesiástico de cierta importancia a principios del siglo X, o São Julião de Mangualde (Marques, 2000: 79-81). El problema surge al intentar datar este fenómeno, sobre todo porque debe partirse de la existencia de cronologías zonales diferenciadas. No cabe duda de que tales manifestaciones funerarias tuvieron un mayor auge en una época de consolidación del papel de los monasterios, sobre todo como consecuencia del hundimiento de la organización episcopal en el ámbito rural.

A pesar de que en Riba Côa no proliferan los ejemplos de articulación de las necrópolis de tumbas excavadas en la roca en torno a centros religiosos de importancia, algunos datos resultan esclarecedores. De nuevo es necesario sacar a relucir el caso de Prazo, ya que la transformación del lugar en un centro de culto en época tardoantigua sirve para constatar un tipo de evolución bastante generalizado en el occidente europeo. Este lugar fue el foco sobre el que pivotó una pequeña necrópolis que se ha podido datar entre los siglos V al IX. Sin embargo, la construcción de una nueva iglesia, probablemente hacia el siglo $\mathrm{X}$, trajo consigo la ampliación de la necrópolis, utilizando sobre todo sarcófagos y tumbas de lajas. En la primera fase, las sepulturas no son reutilizadas - tan sólo hay un caso- y parecen tratarse únicamente de adultos. En cambio, tras la construcción del segundo templo, se reutilizan numerosas sepulturas, posiblemente por la dificultad para crear otras en el entorno inmediato del centro de culto, y aparecen ya algunos individuos no adultos (Coixão, 1999). Una interpretación de esta evolución es que en la primera fase hay una tendencia hacia la concentración de inhumaciones en torno a un centro prestigioso. Pero éste incrementa su preeminencia a lo largo del siglo IX o X, provocando una ampliación del recinto y produciéndose entonces un movimiento más acusado de enterramientos. No muy lejos de allí se encuentra la iglesia de São Pedro de Numão, posiblemente construida entre los siglos X y XI, si bien esta datación responde sobre todo a la existencia 
de tumbas antropomórficas (Lopes, Valente y Barreira, 1998). En cualquier caso, la asociación del templo con una necrópolis relativamente amplia y arremolinada alrededor del lugar de culto implica una tendencia a la concentración de las inhumaciones en torno a determinados centros prestigiosos (Fig. 6). Estos datos empujan a pensar que el proceso de configuración de necrópolis junto a determinados loca sacra se produjo fundamentalmente entre los siglos IX al XI, coincidiendo con la destrucción de las estructuras episcopales, aunque tuvo probablemente un inicio anterior.

Parece, por tanto, que las diferencias internas dentro de la sociedad local se manifestaban en campos distintos de las necrópolis. La inversión destinada al afianzamiento y perpetuación del estatus estaba dirigida sobre todo hacia determinados centros religiosos, que sirven además como legitimación del dominio social. Esta situación permite comprobar el papel crucial de las iglesias y monasterios locales en esta época. Es muy ilustrativo la ausencia de armas y objetos vinculados con el ejercicio de la guerra en una sociedad en la que esa actividad estaba muy extendida y debía ser una de las claves del estatus social (Mattoso, 1987b). Una primera explicación es que este sector no fue una zona destacada por el conflicto militar en época tardoantigua, como sí ocurrió con la Galia septentrional o la Italia central; cuando la función militar adquirió un mayor relieve, es decir, entre los siglos VIII al XI, se había ya producido una intensa cristianización, que impedía la presencia de ajuares vinculados a prácticas guerreras. Además debía utilizarse un equipamiento ligero y la guerra proporcionaba sobre todo un botín en ganado, aspectos que difícilmente se podían reflejar en los depósitos funerarios. No debe desdeñarse el papel eclesiástico a la hora de ordenar los rituales, eludiendo la presencia de ajuares, ni tampoco que el desempeño de las funciones militares estuviera más ligado a una actividad comunitaria que al auge de determinados individuos. La inversión en capital social y simbólico se enfocaría sobre todo en el control de la comunidad y, en especial, en el de las funciones organizativas internas, donde estaba el escenario de la lucha por el dominio social, además de en los centros de culto locales y comarcales.

Las necrópolis no hablan únicamente del estatus, sino también de la ordenación social. Un aspecto destacable es la ausencia de una centralización religiosa de los espacios funerarios. Los yacimientos no se relacionan con las parroquias plenomedievales, ni siquiera en su mayor parte poseen una vinculación con posibles centros de culto. Este tipo de inhumación puede relacionarse con uno de los capitula de san Martín de Dume, el LXVIII, que advierte contra la costumbre de ciertos clérigos de trasladar los oficios y sacramentos en el campo sobre las tumbas de los muertos (Martín de Dume, 1950). Esta práctica parece encubrir un control local del ritual, sin la intervención episcopal, que aspiraba a generar focos de proyección territorial en los que concentrar estas funciones. Los datos del Parrochiale Suevum (PS) pueden interpretarse como los primeros pasos hacia la elaboración de un control diocesano efectivo, a través de algunos centros intermedios dotados del grado de parrochia (Díaz Martínez, 1998). Pero resulta dudosa su eficacia real y desde luego dicho entramado debió entrar en una profunda crisis a partir del siglo VIII. Fue entonces cuando la descentralización de los rituales funerarios debió ser aún más intensa, ya que, tras la conquista musulmana y los problemas suscitados posteriormente por el control del centro peninsular, las sedes episcopales perdieron su, ya de por sí escasa, capacidad para influir en el ámbito rural. Puede observarse nítidamente esta situación a través del caso de Caliabria, lugar que aparece mencionado en el $P S$ como Caliabrica, una parrochia perteneciente al obispado de Viseu (David, 1947: 37). Este núcleo ascendió al rango de obispado posiblemente a principios del siglo VII, ya que las actas del concilio IV de Toledo celebrado en el año 633 fueron confirmadas por el obispo de Caliabria, el primer de una nómina de prelados que se extiende hasta el año 693. Este cambio se debió verificar como consecuencia de la llegada al trono de Witerico (601610), quien encabezaba un grupo de aristócratas lusitanos y cuya familia podría haber recibido importantes bienes en esta zona tras la conquista del reino suevo, lo que explicaría también la existencia de una ceca de corta vida en Caliabria (García Moreno, 1998). El lugar de Caliabria ha sido identificado con Monte do Castelo o Monte Calavre, un promontorio de 505 metros situado en frente del Duero, en la actual población de Almendra (c. Vilanova de Foz Côa), donde se conserva una imponente muralla de pizarra que encierra un recinto en el que apenas se han encontrado algunos bloques de granito trabajados, si bien se menciona la existencia de monedas, ladrillos y algunas estructuras de hábitat (Cabral, 1963; Filipe, 2001). Por otro lado, las excavaciones realizadas en Aldeia Nova-Olival de Telhões, al pie del monte, han ofrecido datos de una intensa ocupación entre los siglos I al VI (Martins y Cosme, 2000); posiblemente fuera aquí donde se asentara el entramado episcopal. La autoridad visigoda, posiblemente a fin de reforzar su dominio sobre esta región, dio un impulso a Caliabria y le concedió un estatus episcopal, generando de esta manera un vector de conexión con las elites locales. Esto no se tradujo necesariamente en una intervención directa del prelado en la actividad de las poblaciones, ya que sin duda tuvo que negociar su 
papel con los grupos de poder locales y las comunidades. La ausencia de restos vinculados a la actividad episcopal pone de manifiesto que la capacidad de influencia de la sede debía ser reducida. Esto explicaría su rápida decadencia tras el colapso del regnum, pero perduró su memoria, posiblemente utilizada por determinados grupos locales y por las autoridades centrales para legitimar sus acciones (Barrios García, 1998) . El resultado de esta débil impronta episcopal, que puede detectarse también en otras zonas de estudio, fue que el ritual funerario quedó en manos de las comunidades.

Estas poblaciones, a pesar de la intervención andalusí -cuya influencia ha quedado reflejada en la presencia de topónimos árabes (Barrios García, 1982; Mattoso, 1987a; Marques, 1999)-, mantuvieron la religión cristiana y una estructura de poder propia. El análisis de las necrópolis de tumbas excavadas en la roca pone de relieve esa pervivencia del cristianismo, ya que se trataba de inhumaciones en las que el cadáver se depositaba en decúbito supino y no en decúbito lateral, como en el caso islámico. Esta sociedad continuó modelos preexistentes y se la puede caracterizar con el término de "mozárabe". No obstante, dicho adjetivo encubre un gran número de situaciones que no pueden asimilarse entre sí. Por esa razón, conviene diferenciar entre unos "mozárabes" urbanos, conectados con ciertos poderes episcopales y con un contacto muy directo con los aparatos políticos andalusí y asturleonés, como ocurriría por ejemplo en Coimbra o Idanha; y los "mozárabes" de áreas rurales, que disponían de sus propias estructuras organizativas autónomas de las urbanas. Los últimos continuaban prácticas ya existentes en el siglo VII y por entonces diferenciadas de las de las ciudades y zonas periurbanas. Este fue el caso de Riba Côa, donde la impronta "mozárabe" impregnó a estos grupos locales. A pesar de la ausencia de referencias sobre este sector durante el periodo andalusí, el papel de focos de articulación territorial de determinados sitios de altura parece haberse incrementado. Así sucedería en Numão y Almeida, y se plasmaría también en la segregación, en la zona meridional fuera de nuestro espacio de estudio, de Sabugal Velho (Silva, 2000b). Estos lugares no fueron creados por poderes centrales ni estuvieron sometidos a los andalusíes, salvo de manera esporádica, ya que no se han encontrado vestigios arqueológicos que lo prueben. Sin embargo, se puede observar la presencia de una toponimia de raíz árabe (Viguera Molins, 1998; Barrios García, 1998), que denuncia tanto la influencia cultural andalusí como la presencia de habitantes en la zona, frente a las teorías clásicas sobre la despoblación (Cintra, 1959). Por otro lado, J. Mattoso (1987b) ya puso de relieve cómo el fuero de Alfayates posee numerosos términos de origen árabe o mozárabe, que encubren precisamente la vigencia de unas estructuras locales propias maduradas en un periodo de ausencia de centralización política.

En definitiva, el estudio de las necrópolis de tumbas excavadas en la roca pone de manifiesto la presencia de una sociedad predominantemente campesina y en sus fases más tardías influida cultural y políticamente por el mundo andalusí, pero no islamizada. En ella hay liderazgos locales relativamente estables, firmemente unidos a las comunidades y a determinados centros de culto. Sin embargo, la intervención de fuerzas externas ligadas a aparatos centralizados fue muy débil, por lo que la legitimación del poder de estos notables se encuentra en las propias comunidades. Todo ello permite hablar de una estabilidad en cuanto a los marcos básicos de organización social, lo que no estuvo exento de transformaciones internas, difíciles aún de apreciar, pero que quizá tengan una constatación en la tendencia a la inhumación en torno a ciertos centros religiosos de especial prestigio. 


\section{BIBLIOGRAFÍA:}

ANDRIO GONZALO, J. (1994): "Dos necrópolis medievales. Quintana María y Cuya Cabras (Burgos)". Boletín de Arqueología Medieval 8, 163-188.

ANDRIO GONZALO, J. et alii (1993): El conjunto arqueológico del monasterio de San Juan de la Hoz de Cillaperlata (Burgos). Burgos.

AZKARATE GARAI-OLAUN, A. y QUIRÓS CASTILLO, J. A. (2001): "Arquitectura doméstica altomedieval en la Península Ibérica. Reflexiones a partir de las excavaciones arqueológicas de la catedral de Santa María de Vitoria-Gasteiz, País Vasco". Archeologia Medievale XXVIII, 25-60.

BARRIOS GARCÍA, Á. (1982): “Toponomástica e historia. Notas sobre la despoblación de la zona meridional del Duero". En la España Medieval, II. Estudios en memoria del profesor D. Salvador de Moxó, 115-134. Madrid.

BARRIOS GARCÍA, Á. (1998): "El proceso de ocupación y de ordenación del espacio en la raya leonesa". O Tratado de Alcanices e a importãncia histórica das terras de Riba Côa, 155-183. Lisboa.

BARROCA, M. J. (1987): Necrópoles e sepulturas medievais de Entre-Douro-e-Minho (séculos V $a X V)$. Oporto.

BARROCA, M. J. (2000): Epigrafia medieval portuguesa. Lisboa.

CABRAL, A. A. Dinis (1963): História da cidade de Calábria em Almendra (subsídios). Oporto.

CASTILlO, A. del (1970): "Cronología de las tumbas llamadas olerdolanas". XI Congreso Nacional de Arqueología, 835-845. Zaragoza.

CASTILLO, A. del (1972): Excavaciones altomedievales en las provincias de Soria, Logroño y Burgos. Madrid.

CHAVARRÍA ARNAU, A. (2001): "Villae y necrópolis en Hispania durante la Antigüedad tardía". Bulletin Association pour l'Antiquité tardive 10, 44-57.

CINTRA, L. F. Lindley (1959): A linguagem dos foros de Castelo Rodrigo. Lisboa.

COIXÂO, A. N. Sá (1999): Rituais e cultos da morte na região de entre Douro e Côa. Almada.
COIXÂO, A. N. Sá (2000): Carta arqueológica do concelho de Vila Nova de Foz Côa. Vila Nova de Foz Côa ${ }^{2}$.

COLMENAREJO GARCÍA, F. (1986): "El yacimiento arqueológico de Fuente del Moro". I Congreso de Arqueología Medieval Española, II, 221-239. Zaragoza.

COLMENAREJO GARCÍA, F. (1987): Arqueología medieval de Colmenar Viejo. Madrid.

COSME, S. Ma Rodrigues (2002): Entre o Côa e o Águeda. Povoamento nas épocas romana e alto-medieval. Oporto (Dissertação de mestrado em Arqueología, inédita).

DA COSTA, A. de Jesus y MARQUES, $\mathrm{M}^{\mathrm{a}}$ A. F. (1990): Bulário portugués. Inocencio III (11981216). Lisboa.

DAVID, P. (1947): Études historiques sur la Galice et le Portugal. Coimbra.

DÍAZ MARTÍNEZ, P. C. (1998): "El Parrochiale Suevum: organización eclesiástica, poder político y poblamiento en la Gallaecia tardoantigua". Homenaje a José M $M^{a}$ Blázquez, VI, 35-47. Madrid.

ENDOVELICO: Base de datos de sitios arqueológicos "Endovelico" del IPA www2.ipa.min-cultura.pt.

ESCALONA MONGE, J. (2002): Sociedad y territorio en la Alta Edad Media castellana. La formación del alfoz de Lara. Oxford.

ESTEPA DÍEZ, C. (1977): Estructura social de la ciudad de León (siglos XI-XIII). León.

FABIÁN, J. F. et alii (1986): "Los poblados hispanovisigodos de "Cañal", Pelayos (Salamanca). Consideraciones sobre el poblamiento entre los siglos V y VIII en el SE de la provincia de Salamanca". I Congreso de Arqueología Medieval Española, II, 187-202. Zaragoza.

FERREIRA, Ma C. Crespo (2000): "Contributos para a carta arqueológica do concelho de Trancoso". Beira interior. História e Património. Actas das I Jornadas de Património da Beira Interior, 361-374. Guarda.

FILIPE, S. M. de Jesús (2001): Diócesis calabriensis, sede e territorio. Coimbra (Trabalho do seminario em Arqueología, inédito).

FRANCOVICH, R. y HODGES, R. (2003): Villa to Village. The Transformation of the Roman Countryside in Italy, c. 400-1000. Londres.

GARCÍA DE FIGUEROLA PANIAGUA, M. (1999): Arqueología romana y altomedieval de la 
Sierra de Gata (El Valle de Valverde. Provincia de Cáceres). Cáceres.

GARCÍA MORENO, L. Á. (1998). "Riba Côa en el periodo visigodo". O tratado de Alcanices e a importancia histórica das terras de Riba Côa, 115-130. Lisboa.

GOMES, M. Varela (2002): "A necrópole visigótica do Poço dos Mouros (Silves)". Revista Portuguesa de Arqueología 5-2, 339-391.

GONZÁLEZ, J. (1944): Alfonso IX. Madrid.

GONZÁLEZ, J. (1980-86): Reinado y diplomas de Fernando III. Córdoba.

GONZÁLEZ CORDERO, A. (1998): "Los sepulcros excavados en la roca de la provincia de Cáceres". Los visigodos y su mundo, 271-284. Madrid.

GUIMARÂES, G. (2000): "Vestígios paleocristãos de Ervamoira. Vale do Côa". $3^{\circ}$ Congresso de Arqueologia Peninsular, VI, 617-631. Oporto.

GUTIÉRREZ DOHIJO, E. (2001): “¿Dos necrópolis entre la Antigüedad y el Medievo?" El Quintanar de Montejo de Tiermes y la rupestre de Tiermes (Soria)", $V$ Congreso de Arqueología Medieval Española, I, 115-123. Valladolid.

HALSALL, G. (1997): Early Medieval cemeteries. An introduction to burial archaeology in the Post-Roman West. Londres.

LA ROCCA, C. (1998a): "La trasformazione del territorio in Occidente". Morfologie sociali e culturali in Europa fra Tardo Antichità e Alto Medioevo, I, 257-290. Spoleto.

LA ROCCA, C. (1998b): "Donare distribuire, spezzare. Pratiche di conservazione della memoria e dello status in Italia tra VIII e IX secolo". BROGIOLO, G. P. y CANTINO WATAGHIN, G. (eds.), Sepulture tra IV e VIII secolo, 77-87. Mantua.

LOPES, A., VALENTE, H. y BARREIRA, P. (1998): "Vila Velha de Numão, um projecto de investigação em curso". Terras do Côa. Da Malcata ao Reboredo. Os valores do Côa, 2429. Guarda.

LÓPEZ QUIROGA, J. (2004): El final de la Antigüedad en la Gallaecia. La transformación de las estructuras de poblamiento entre Miño y Duero (siglos $V$ al X). La Coruña.

LÓPEZ QUIROGA, J. y RODRÍGUEZ LOVELLE, M. (1992): "Propuesta de cronología e interpretación histórica de los enterramientos en piedra en Galicia durante la Alta Edad Media (ss. V-XI)". Boletín de Arqueología Medieval 6, 139-155.

LÓPEZ QUIROGA, J. y RODRÍGUEZ LOVELLE, M. (1999): "L'habitat dispersé de la Galice et du Nord du Portugal entre le $\mathrm{V}^{\mathrm{e}}$ et le $\mathrm{X}^{\mathrm{e}}$ siècle. Essai d'intepretation à partir de l'analyse macro et microrégionale". CURSENTE, B. (ed.), L'habitat dispersé dans l'Europe médiévale et moderne, 97-119. Toulouse.

MARQUES, J. A. de Meneses (1999): Carta arqueológica do concelho de Vouzela. Vouzela.

MARQUES, J. A. de Meneses (2000): Sepulturas escavadas na rocha na região de Viseu. Viseu.

MARTÍN DE DUME (1950): Opera omnia. Londres (BARLOW, C. W., ed.).

MARTÍN MARTÍN, J. L. (1989): Documentación medieval de la iglesia catedral de Coria. Salamanca.

MARTÍN VISO, I. (2000): Poblamiento y estructuras sociales en el norte de la Península Ibérica (siglos VI-XIII). Salamanca.

MARTÍN VISO, I. (2002a): Fragmentos del Leviatán. La articulación política del espacio zamorano en la Alta Edad Media. Zamora.

MARTÍN VISO, I. (2002b): "Espacio y poder en los territorios serranos de la región de Madrid (siglos X-XIII)". Arqueología y Territorio Medieval 9, 53-84.

MARTINS, C. M ${ }^{\mathrm{a}}$ Braz y COSME, S. Rodrigues (2000): "O contributo do espólio cerãmico na interpretação da estação arqueológica de Aldeia Nova/ Olival dos Telhões (Freguesia de Almendra, concelho de Vila Nova de Foz Côa)". Beira interior. História e Património. Actas das I Jornadas de Património da Beira Interior, 159-170. Guarda.

MATTOSO, J. (1987a): “Os moçárabes". Fragmentos de uma composição medieval, 1934. Lisboa.

MATTOSO, J. (1987b): "Da comunidade primitiva ao municipio. O exemplo de Afaiates". Fragmentos de uma composição medieval, 3548. Lisboa.

MÍNGUEZ, J. Ma (2000). "La despoblación del Duero: un tema a debate". PÉREZ, J. y AGUADÉ NIETO, S. (eds.), Les origines de la 
féodalité. Hommage à Claudio SánchezAlbornoz, 169-182. Madrid.

MORERE MOLINERO, N. (1986): "Dos conjuntos de tumbas antropomorfas de la meseta sur: provincias de Guadalajara y Madrid". I Congreso de Arqueología Medieval Española, $\mathrm{V}, 275-288$. Zaragoza.

NUÑO GONZÁLEZ, J. (1997-98): “La Huesa (Zamora): ¿un asentamiento altomedieval en el “desierto" del Duero?". Numantia 8, 137-194.

PADILLA LAPUENTE, J. I. (2003): Yacimiento arqueológico de Cuyacabras. Despoblado, iglesia y necrópolis. Eremitorio de Cueva Andrés. Quintanar de la Sierra (Burgos). Barcelona.

PALACIOS MARTÍN, B. (dir.) (2000): Colección diplomática medieval de la Orden de Alcántara (1157?-1494). I. De los orígenes a 1454. Madrid.

PERESTRELO, M. S. G. (2000): O povoamento romano na bacia média do rio Côa e na bácia da ribeira de Massueme. Coimbra (tese de mestrado inédita).

PINTO, A. Nunes (1983): "Notas sobre a necrópole medieval da igreja matriz de Mangualde". Mundo da Arte 16, 67-70.

REYES TÉLLEZ, F. y MENÉNDEZ ROBLES, M ${ }^{\mathrm{a}}$ L. (1985): "Excavaciones en la ermita de San Nicolás. La Sequera de Haza (Burgos)". Noticiario Arqueológico Hispánico 26, 163213.

RODRIGUES, A. Vasco (1992): Celorico da Beira e Linhares. Monografia histórica e artística. Celorico da Beira.

SÁNCHEZ CABAÑAS, A. (2001): Historia civitatense. Ciudad Rodrigo (BARRIOS GARCÍA, Á. y MARTÍN VISO, I., eds.).

SÁNCHEZ-ALBORNOZ, C. (1966): Despoblación y repoblación del valle del Duero. Buenos Aires.

SERRANO PEÑA, J. L. y CASTILLO ARMENTEROS, J. C. (2000): "Las necrópolis medievales de Marroquíes Bajos (Jaén). Avance de las investigaciones arqueológicas". Arqueología y Territorio Medieval 7, 93-120.

SILVA, M. D. Osório da (2000a): O povoamento romano do alto Côa. Coimbra (Dissertaçâo de mestrado inédita).

SILVA, M. D. Osório da (2000b): "O Sabugal Velho. Primeiras achegas para o estudio de uma estação arqueológica". Beira interior. História e Património. Actas das I Jornadas de Património da Beira Interior, 209-214. Guarda.

TAVARES, A. L. Marques (1999): Sepulturas escavadas na rocha no concelho de Mangualde. Mangualde.

TENTE, C. y LOURENÇO, S. (1998): "Sepulturas medievais escavadas na rocha dos concelhos de Carregal do Sal e Gouveia: estudo comparativo". Revista Portuguesa de Arqueología 1-2, 191-218.

VALERA, A. C. (1993): Património arqueológico do concelho de Fornos de Algodres. Lisboa.

VIEIRA, M. A. (2000): Alto Paiva. Povoamento nas épocas romana e alto-medieval. Coimbra (dissertação de mestrado inedita).

VIGIL-ESCALERA GUIRADO, A. (2000): "Cabañas de época visigoda: evidencias arqueológicas del sur de Madrid. Tipología, elementos de datación y discusión". Archivo Español de Arqueología 73, 223-252.

VIGUERA MOLINS, M ${ }^{\mathrm{a}} \mathrm{J}$., "En torno a Riba Côa y al-Andalus". O tratado de Alcanices $e$ a importãncia histórica das terras de Riba Côa, 131-152. Lisboa.

WICKHAM, C. (1989): "La otra transición: del mundo antiguo al feudalismo". Studia Historica. Historia Medieval VII, 7-35.

YÁÑEZ, G. I. et alii (1994): "Excavaciones en el conjunto funerario de época hispano-visigoda de La Cabeza (La Cabrera, Madrid)". Pyrenae 25, 259-287. 
Fig. 1. Necrópolis de tumbas excavadas en la roca en Riba Côa

Fig. 2. Necrópolis de Vale da Igreja (Azinhal, c. Almeida) 


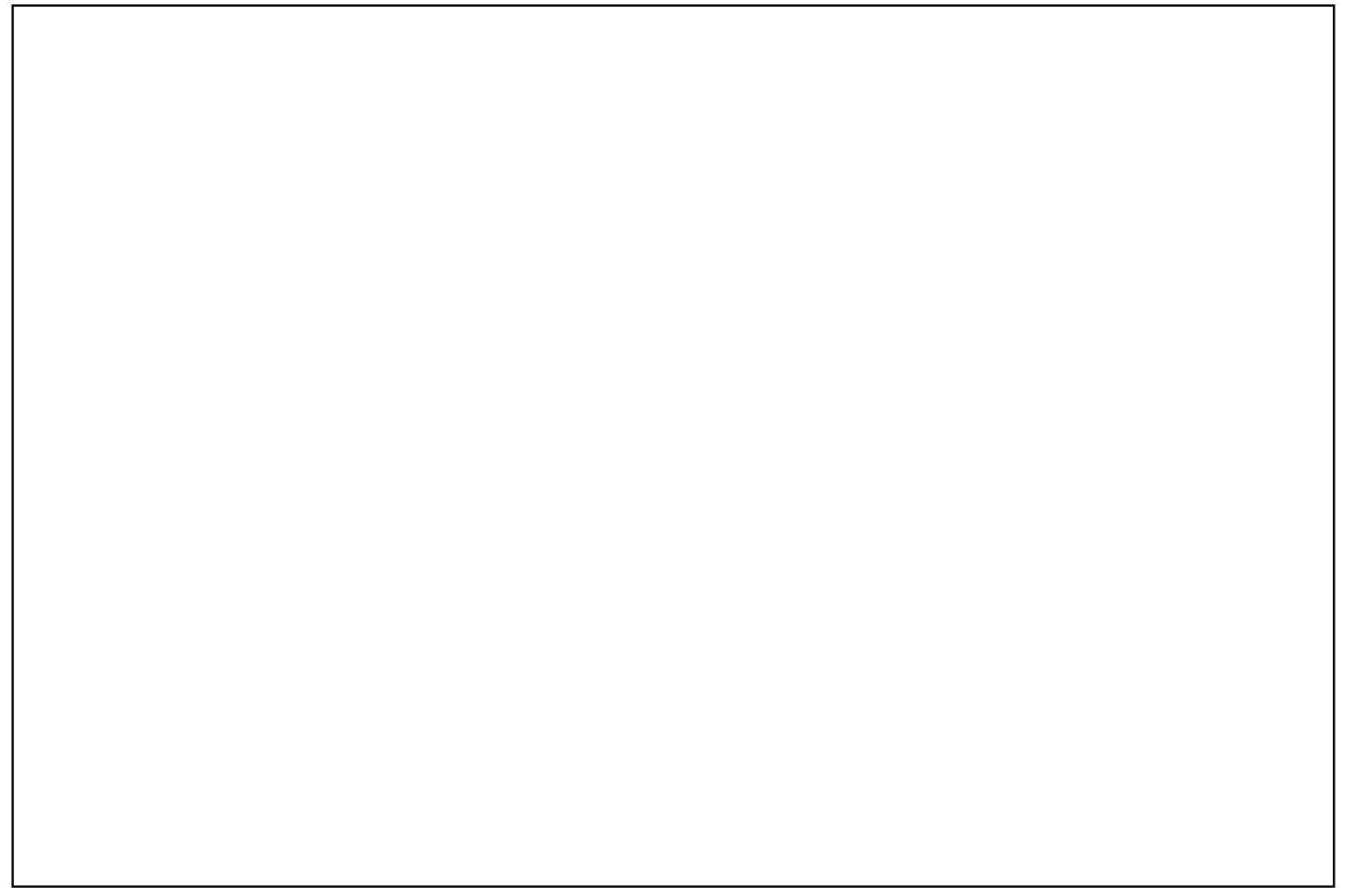

Fig. 3. El yacimiento de Telhões (Leomil, c. Almeida) 


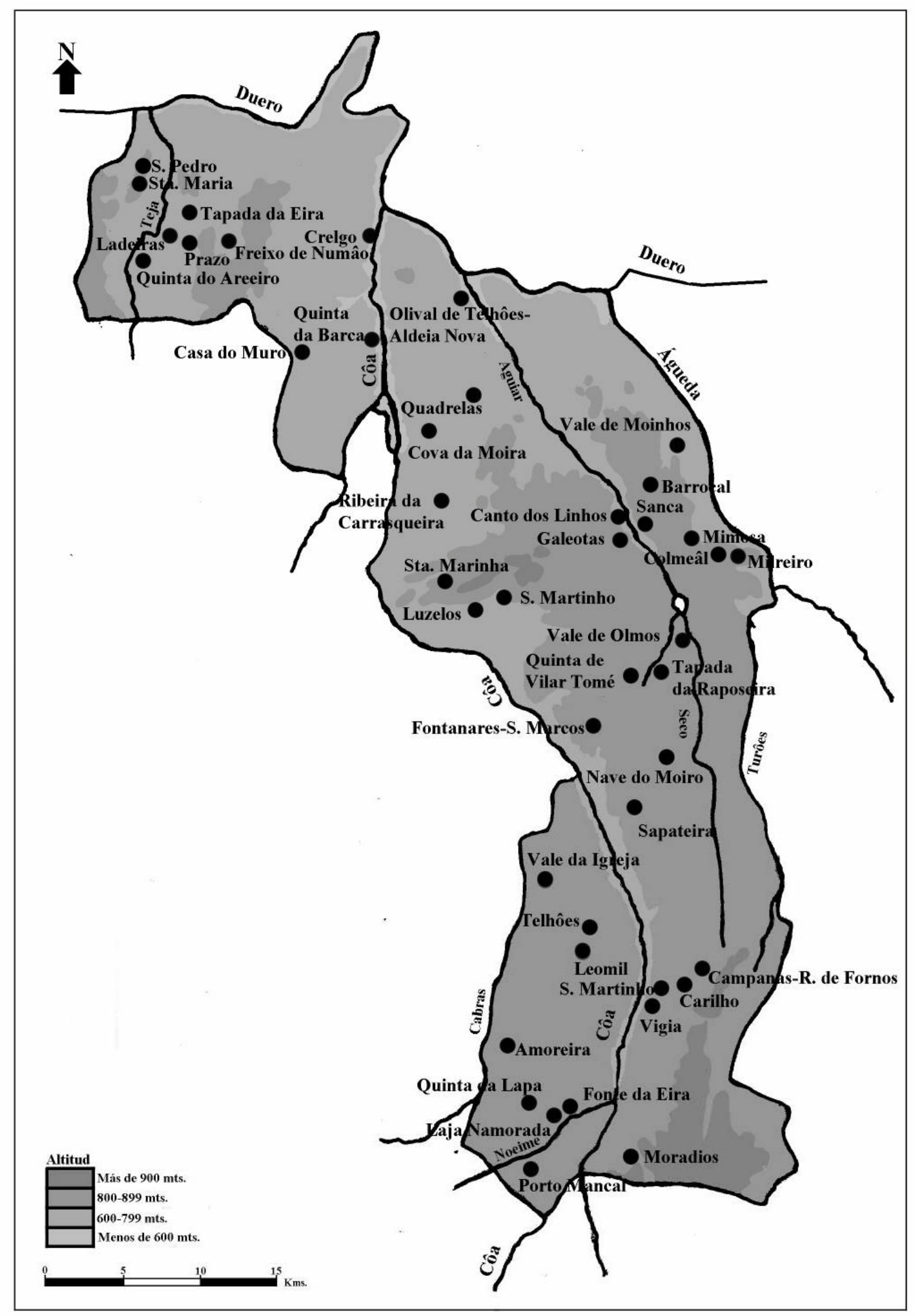

Fig. 4. Yacimientos con tumbas excavadas en la roca asociados a restos tardorromanos y altomedievales en Riba Côa 


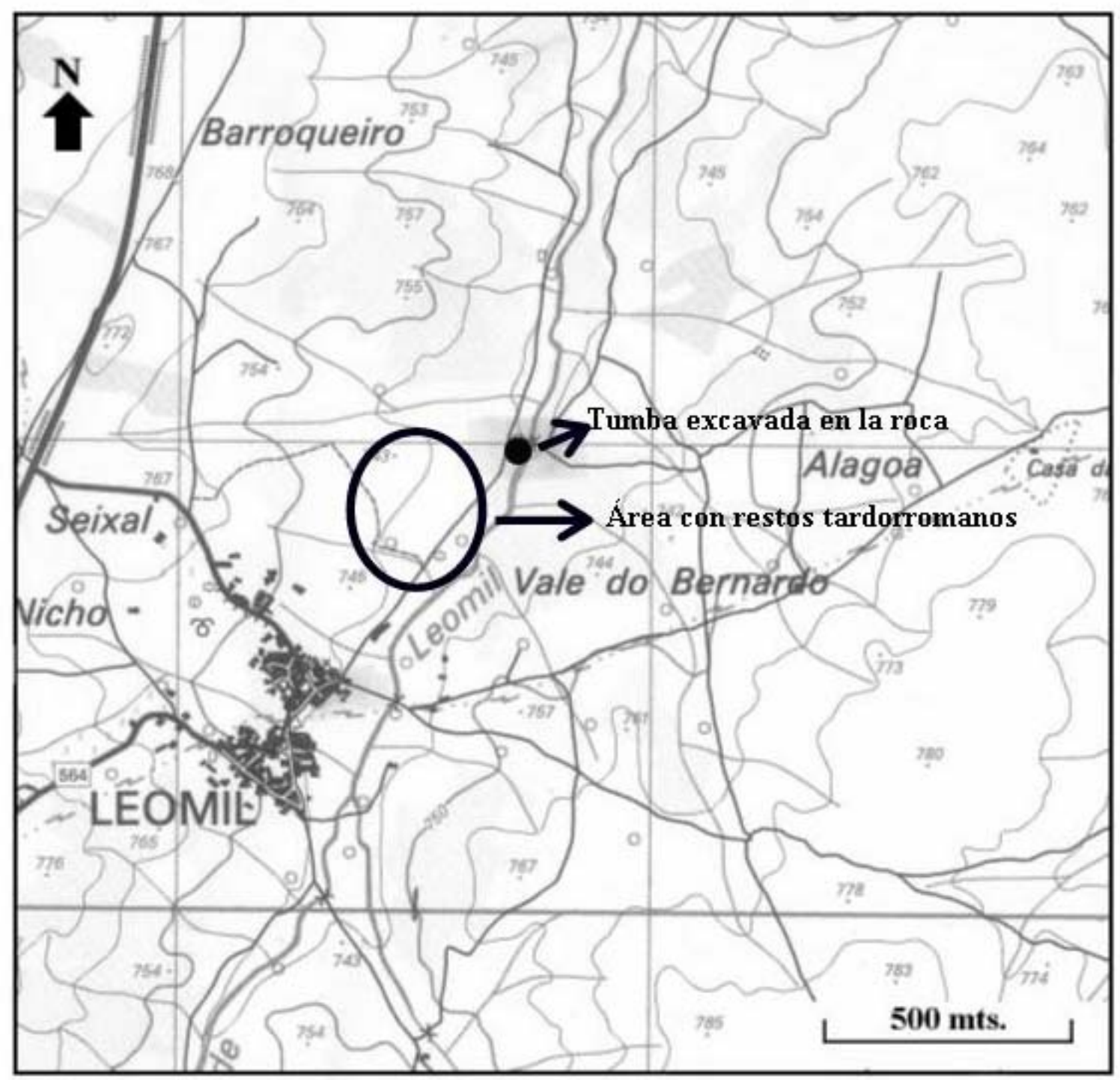

Fig. 5. La necrópolis de Tapada da Raposeira (Vermiosa, c. Figueira de Castelo Rodrigo) 


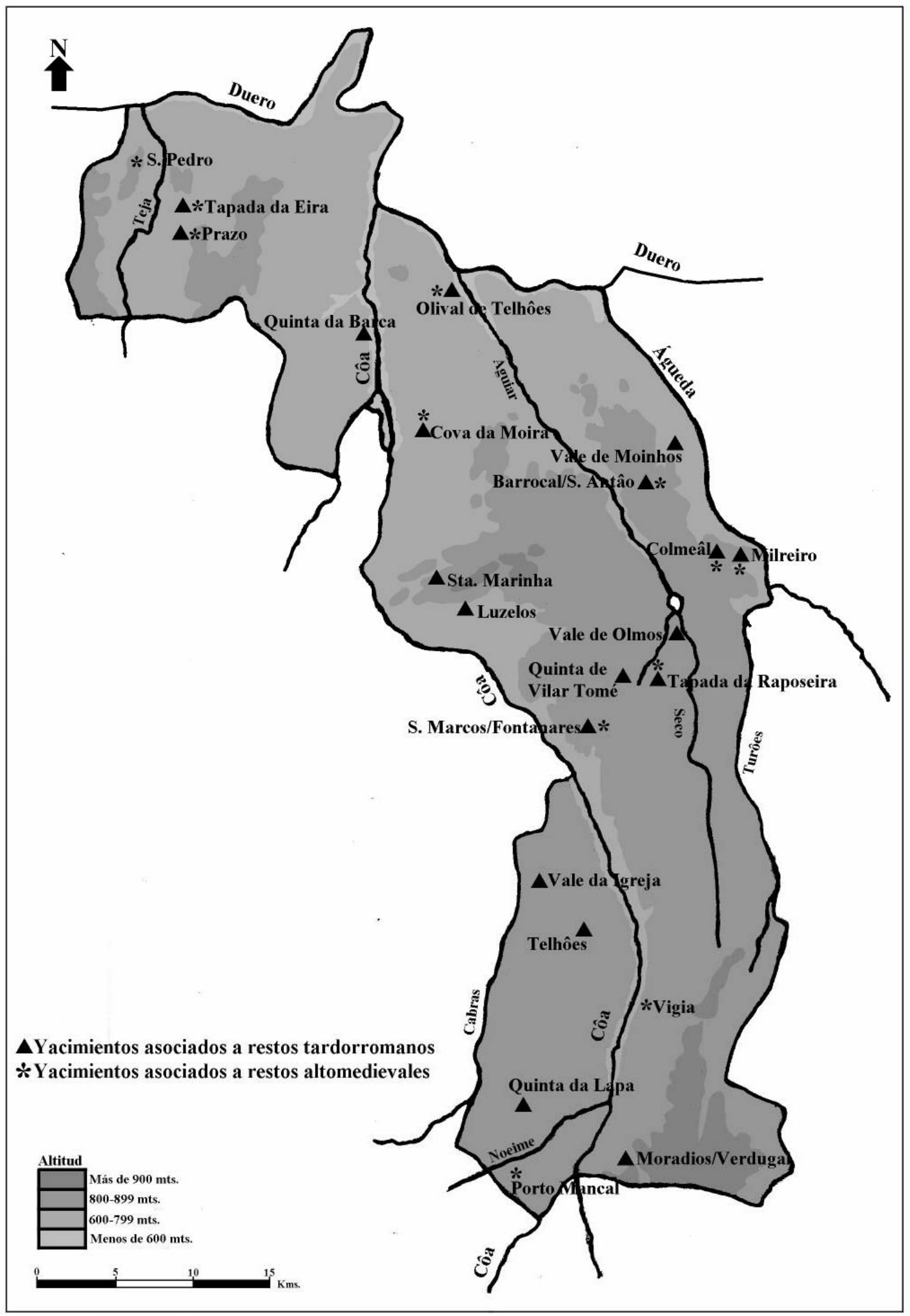

Fig. 6. La necrópolis de São Pedro de Numão (c. Vila Nova de Foz Côa) 